\title{
Invasiveness of Salmonella serotypes Typhimurium and Enteritidis of human gastro-enteritic origin for rabbit ileum: role of LPS, plasmids and host factors
}

\author{
GILLIAN D. MARTIN, HENRIK CHART*, E. JOHN THRELFALL*, EIRWEN MORGAN, \\ JULIA M. LODGE, NIGEL L. BROWN and JOHN STEPHEN
}

Microbial Molecular Genetics and Cell Biology Group, School of Biological Sciences, University of Birmingham, Edgbaston, Birmingham B15 2TT and * Laboratory of Enteric Pathogens, Public Health Laboratory Service, 61 Colindale Avenue, London NW9 5HT

\begin{abstract}
An organ culture system involving explants of distal rabbit ileum was used to study the roles of lipopolysaccharide (LPS) and plasmids in primary invasiveness for enterocytes in situ of strains of Salmonella serotypes Typhimurium and Enteritidis. Long-chain LPS per se does not confer invasiveness on Typhimurium, as known avirulent, hypo-invasive strains express smooth LPS. However, the invasiveness of a naturally occurring rough isogenic derivative of Salmonella serotype Enteritidis PT 4 was about half that of its wild-type parent. Therefore, smooth LPS appears to play a secondary role in maximising invasiveness. No evidence was found to correlate primary invasiveness for gut of 18 strains of Typhimurium with plasmid profiles in general or with the 60-MDa serovar-specific virulence plasmid in particular. Evidence is presented that strongly suggests a seasonal variability in susceptibility of rabbit gut to invasion by Typhimurium. Although no explanation is given for this summer insusceptibility, the data indicate the importance of the physiological status of the host in relation to susceptibility to invasion by Salmonella.
\end{abstract}

\section{Introduction}

This report describes experiments with strains of Salmonella serotypes Typhimurium and Enteritidis which were designed to address questions as to the involvement of lipopolysaccharide (LPS) and plasmids in initial invasion of gut epithelia. The role(s) of LPS and plasmids in determining virulence in Salmonella are not entirely clear.

Elucidation of the structure and biosynthesis of LPS and its role and mechanism(s) of action in systemic infections caused by gram-negative pathogens has been a major focus during the last decade, leading to several International Symposia [1-5] and a Journal of Endotoxin Research. Its bewildering range of properties makes the design and execution of biologically definitive experiments very difficult. The first direct demonstration of the lethality to mice of lipid A was

Received 24 Jan. 2000; revised version received 2 April 2000; accepted 4 April 2000.

Corresponding author: Dr J. Stephen (e-mail: J.Stephen@, bham.ac.uk). made only recently [6]. Earlier classic biological experiments with related Typhimurium strains with and without long-chain LPS showed that possession of smooth LPS was an important virulence attribute of Typhimurium in mice infected intraperitoneally [7-10], with some LPS chemotypes more virulent than others $[10,11]$. Differences in virulence were shown to correlate with differences in susceptibility to phagocytosis [12] and the capacity of LPS to activate complement via the alternate pathway [13-17].

The data on LPS and invasion are unclear and sometimes contradictory. Rough mutants of Typhimurium, defective in the core region and O-side chain of their LPS, were less invasive than smooth strains for the ileum of specific pathogen-free mice inoculated intra-gastrically [18]. The ability of Salmonella serotype Typhi to invade HeLa cells was dependent on the presence of complete LPS, as rough mutants failed to invade HeLa cells; failure was ascribed to impaired adhesion to cells [19]. However, pre-treatment of HeLa cell monolayers with purified LPS did not inhibit the invasiveness of viable organisms, from which it was deduced that either LPS was not the primary ligand for 
adhesion, or that purified LPS was in the incorrect configuration to act as a blocking agent [19]. Three rough ( $r f a)$ mutants of Typhimurium caused significantly less fluid loss in rabbit ileal loop tests (RILTs) than the parent strain [20]. Histological studies revealed that the LPS mutants were less invasive than wild-type strains, less able to generate inflammatory reactions, induce influxes of polymorphonuclear leucocytes (PMNL) and cause damage to rabbit ileal villus morphology [20]. Tn phoA mutants of Salmonella serotype Choleraesuis have been described with altered LPS profiles that were unable to invade MDCK cells [21].

However, other findings conflict with those presented above. For example, pre-treatment of HeLa cells with LPS enhanced rather than blocked attachment of Typhimurium to HeLa cells [22]. Invasion of Caco-2 and J774 (cultured macrophages) cells by $80 \mathrm{Tn} 10$ mutants of Typhimurium was independent of LPS composition [23]. It has been shown that three rough Tn phoA insertion mutants of Typhimurium strain TML displayed parental or $50 \%$ parental levels of invasiveness in HEp-2 cells, although these same mutants all exhibited c. $10 \%$ parental levels of invasiveness in rabbit ileal explants [24].

Gut invasion data obtained in whole animal experiments are often difficult to interpret, as the distinction between cell invasion of gut epithelia and tissue spread through the lamina propria and beyond is often hard to make, or not taken into account in the first place. Also, several groups [25-27] have highlighted the importance of the genetic background of the murine host strain used in determining its susceptibility to Salmonella, which makes the extrapolation of data from mice to other species even more difficult. Again, ascribing loss of invasiveness of rough laboratory-generated LPS mutants directly to the loss of LPS side-chains can be criticised on several grounds. For example, unless Tn phoA LPS mutants are rigorously characterised genetically it is not always possible to distinguish between two possible explanations for reduced invasiveness [24]. First, it could be that LPS is involved in assisting invasion. Second, the rough phenotype may not be a result of the insertion of the transposon into a gene involved in the synthesis of LPS, but may result from the selection of spontaneously arising rough mutants which may serve as better recipients for conjugation; in this case the non-invasive phenotype could result from a separate mutation [24]. Clearly this could apply to other similarly produced mutants. Also, it is now thought that LPS is involved in intracellular survival of salmonellae, probably by interacting with antimicrobial peptides $[28,29]$. Therefore, it is important to limit the duration of any invasion assay to as short a time as possible, as the effectiveness of such invasion assays is usually determined in terms of the numbers of tissue- (or cell-) protected bacteria recovered; lengthy tests could reflect intracellular survival as well as primary invasion. Other studies also suggest that LPS influences the function or secretion of surface proteins [30,31]. Given that at least some of the invasins for eukaryotic cells already recognised in Salmonella are secreted by type III systems [32,33], alterations in the structure of LPS could be responsible for lowering of invasion by secondary rather than primary means.

Serovar-specific virulence plasmids (SSPs) are implicated in systemic salmonellosis caused by Salmonella serotype Gallinarum in poultry [34], Choleraesuis in pigs [35], several Salmonella serotypes in mice [36] and Dublin in calves [37]. The role of SSPs in systemic infections is at present unclear and highly complex; they are not equally necessary for virulence in all serotypes (or phage types within a serotype) [37]. In serotype Typhi, no association was found with any plasmid or plasmid profile and severity or clinical manifestation of disease [38]. Recent studies show that for some Salmonella serotypes, plasmid carriage can be positively disadvantageous for bacteria growing in serum [39]. Several studies have shown that SSPs are not involved in the translocation of serotypes Dublin [40] and Typhimurium [41] through murine intestinal mucosae. Recently, it was shown that the SSP of serotype Dublin was not involved in the causation of enteritis in calves [37].

In this paper, both plasmid and LPS profiles of 17 Typhimurium strains and three Enteritidis strains were examined and correlated with previously existing and new gut invasion data in an attempt to evaluate the significance of plasmids (in particular SSPs) and LPS in the invasion of explants of rabbit distal ileum by strains of Typhimurium and Enteritidis phage type (PT) 4 isolated from human cases of gastro-enteritis. The distinctive feature of this analysis is that the invasion data were obtained from a gut organ culture system developed in this laboratory, the rabbit ileal invasion assay (RIIA) in which explants of distal rabbit ileal mucosa [42] are used for the study of the initial invasiveness for gut epithelia of different Salmonella serotypes [24, 42, 43]. This is a short duration test and measures bacterial invasion of enterocytes in situ and is, therefore, potentially free from the criticisms raised above about longer term experiments.

Also, some rather unexpected findings on the seasonal susceptibility of rabbit gut to invasion by Salmonella serotype Typhimurium are reported.

\section{Materials and methods}

\section{Bacterial strains}

Salmonella serotype Typhimurium strains. 'Biologically characterised strains' (TML, WII8, WAKE, LT7, SL1027, M206 and Thax-1) comprise a panel of strains that have been studied quantitatively in this 
laboratory in terms of their ability to (i) induce both fluid secretion [44, 45] and PMNL influxes [46] in rabbit ileal loops, and (ii) invade rabbit ileal epithelia as measured in rabbit ileal invasion assays (RIIAs) $[24,42,43]$. Strains GM1-10 are more recently isolated human strains whose invasiveness has been measured relative to TML in the RIIA [43]. Throughout this and previous work, TML has been used as the standard invasive strain with which all others are compared and to which they are normalised in quantitative experiments. See Table 1 for a description of Typhimurium strains.
Salmonella serotype Enteritidis strains. Enteritidis PT 4 (strain P132344 [39]), contains a 38-MDa SSP. Enteritidis PT4(-) (strain P132344/1 [39]), is a spontaneous 38-MDa SSP-free segregant of strain P132344 identified by plasmid analysis of subcolonies recovered after continuous cultivation of the parent strain for $72 \mathrm{~h}$ [39]; no plasmid virulence genes were detected in the chromosome with probes designed to detect $s p v$ genes (unpublished observations). Enteritidis PT 7 (strain E1492 [39]) is a rough isogenic mutant of Enteritidis PT 4 which arises spontaneously from Enteritidis PT 4 in culture, or passage through eggs; LPS side-chains

Table 1. Summary of properties of Salmonella strains

\begin{tabular}{|c|c|c|c|c|c|c|c|}
\hline \multirow{3}{*}{$\begin{array}{l}\text { Strain } \\
{[\text { Refs }]^{*}}\end{array}$} & \multicolumn{5}{|c|}{ Previously described (unless otherwise stated) } & \multicolumn{2}{|c|}{$\begin{array}{c}\text { This work } \\
\text { (unless otherwise stated) }\end{array}$} \\
\hline & \multirow{2}{*}{$\begin{array}{l}\text { Phage } \\
\text { type }\end{array}$} & \multicolumn{3}{|c|}{ Invasiveness $^{\dagger}$} & \multirow[b]{2}{*}{ Virulence } & \multirow{2}{*}{$\begin{array}{l}\text { Plasmids }^{\S} \\
\text { (number:MDa) }\end{array}$} & \multirow[b]{2}{*}{ LPS $\|$} \\
\hline & & Hyperinvasive & Hypo-invasive & \%TML/P132344 & & & \\
\hline \multirow{2}{*}{\multicolumn{8}{|c|}{$\begin{array}{l}\text { Typhimurium } \\
\text { Biologically } \\
\text { characterised } \\
{[24,42-45]}\end{array}$}} \\
\hline & & & & & & & \\
\hline TML & PT32 & + & & & $\mathrm{V}$ & 2:c. 60 & Smooth \\
\hline W118 & PT32 & + & & & $\mathrm{V}$ & 2: c. 60 & Smooth \\
\hline WAKE & PT49 & + & & & $\mathrm{V}$ & 1: c. 60 & Smooth \\
\hline LT7 & PT46 & & + & & $\mathrm{AV}$ & 2: c. 60 & Smooth \\
\hline SL1027 & PT1 & & + & & $\mathrm{AV}$ & 1: c. 60 & Smooth \\
\hline M206 & PT126 & & + & & $\mathrm{AV}$ & None & Smooth \\
\hline Thax-1 & PT52 & & + & & $\mathrm{AV}$ & 2: c. 60 & Smooth \\
\hline \multicolumn{8}{|c|}{ GM series [43] } \\
\hline $\begin{array}{l}\text { Group } 1 \\
\text { GM3 } \\
\text { Group } 2\end{array}$ & PTU285 & & & Histotoxic [52] & $\mathrm{V}$ & Small plasmids & Smooth \\
\hline GM5 & PT12 & & & $40-60$ & $\mathrm{~V}$ & 1: c. 60 & Smooth \\
\hline GM6 & PT107 & & & $40-60$ & V & 1: c. 60 & Smooth \\
\hline $\begin{array}{l}\text { GM8 } \\
\text { Group } 3\end{array}$ & PT135 & & & $40-60$ & V & 1: c. 60 & Smooth \\
\hline GM4 & PT8 & & & $60-80$ & $\mathrm{~V}$ & 1: c. 60 & Smooth \\
\hline $\begin{array}{l}\text { GM10 } \\
\text { Group } 4\end{array}$ & PT49 & & & $60-80$ & $\mathrm{~V}$ & 1: c. 60 & Smooth \\
\hline GM1 & РT203 & & & $80-c .100$ & V & 1: c. 60 & Smooth \\
\hline GM2 & PT170 & & & $80-$ c. 100 & $\mathrm{~V}$ & Small plasmids & Smooth \\
\hline GM7 & PT141 & & & $80-c .100$ & $\mathrm{~V}$ & 1: c. 60 & Smooth \\
\hline GM9 & PT104 & & & $80-$ c. 100 & $\mathrm{~V}$ & 1: c. 60 & Smooth \\
\hline \multicolumn{8}{|l|}{ Enteriditis [39, 47] } \\
\hline P132344 & PT4 & & & 100 & $\mathrm{~V}$ & $38[39,47]$ & $\begin{array}{l}\text { Smooth } \\
{[39,47]}\end{array}$ \\
\hline $\mathrm{P} 132344 / 1^{* *}$ & PT4 & & & $?^{\dagger \dagger}$ & $?$ & No $38 \mathrm{MDa}$ & smooth \\
\hline E1492 & PT7 & & & c. 50 & $?$ & $38^{* t}$ & Rough \\
\hline
\end{tabular}

* References for previously described properties. 'Biologically characterised' strains refers to a panel of strains used extensively in previous work from this laboratory. Some had been tested in monkeys, all had been tested in RILT for fluid production and induction of PMNL influx, and in quantitative invasion assays in RIIA in vitro.

${ }^{\dagger}$ For the biologically characterised strains, invasiveness was determined in RIIA which discriminated these strains into hyperinvasive and hypoinvasive groups. The GM series was tested in RIIA with TML as a positive control; the data are expressed relative to TML. In contrast to the Typhimurium invasion data in this table which are taken from previous cited work, the Enteritidis invasion data are expressed in relation to strain P132344 and were obtained in this work.

* This was determined either in terms of clinical origin (TML, W118, WAKE, GM series, P132344 were all of human origin), or behaviour in monkeys/rabbits, or both (biologically characterised series). The gastro-enteritic potential of P132344/1 and E1492 is not known. V, virulent; $\mathrm{AV}$, avirulent.

$\S$ The 60-Mda plasmid is the serotype-specific plasmid of Typhimurium; the 38-MDa plasmid is the serotype-specific plasmid of Enteritidis. The term serotype-specific is used instead of 'virulence-associated plasmid', as suggested earlier [26]. For the GM series a variety of small plasmid profiles was observed (see Fig. 4).

"LPS is described as smooth if a long side-chain ladder pattern was observed and rough if long side-chain pattern was absent.

** Spontaneously arising 38-MDa plasmid-minus segregant of P132344.

${ }^{\dagger}$ Comparable invasiveness to P132344 in one experiment.

thef. 47. Enteritidis strain containing 38-MDa plasmid but lacking LPS side-chains. 
are lost at a frequency of 1:10 [47]. PT 7 has never been found to revert to PT 4 and does not appear to be associated with disease in man. See Table 1 for a description of strains.

\section{Storage of bacterial strains, and culture media and conditions}

These were all as described previously $[42,43]$.

\section{Animals}

New Zealand White Rabbits $(2.5-3.0 \mathrm{~kg})$ supplied by Froxfield (Hampshire, UK) were used to obtain intestinal tissue for experiments. They were observed for any gastrointestinal manifestations and were used only if found to be symptom-free. Careful records were kept as to when they were purchased and used.

\section{Organ culture}

Apparatus and use were as described previously [42]. Briefly, rabbit terminal ileum segments were obtained from anaesthetised animals, stripped of muscle layers and the mucosae were mounted in a 12-chamber apparatus. The mucosal and serosal sides of each chamber were bathed with solutions designed to maintain tissue viability for up to $4 \mathrm{~h}$ [42].

\section{Rabbit ileal invasion assays (RIIAs)}

Assays were performed as described previously [42]. In each assay, Typhimurium TML was used as an internal positive control to enable comparisons to be made between experiments conducted at different times with gut from different animals.

\section{LPS profiles}

LPS was prepared from whole bacteria by the proteolytic digestion of cellular proteins with proteinase $\mathrm{K}$ [47]. After SDS-PAGE, gels were fixed in acetic acid $5 \% \mathrm{v} / \mathrm{v}$ containing methanol $40 \% \mathrm{w} / \mathrm{v}$ and then stained with silver [48].

\section{Plasmid profiles}

Partially purified plasmid DNA was extracted for plasmid profile determination [49]. In one experiment (Fig. 4) electrophoresis was performed in agarose $0.7 \% \mathrm{w} / \mathrm{v}$ in Tris-borate, $\mathrm{pH} 8$, at $100 \mathrm{~V}$. For a second experiment (Fig. 5), agarose $0.6 \% \mathrm{w} / \mathrm{v}$ was used and the gel was run for longer. This was done in an attempt to resolve the large plasmid band in TML, which in a preliminary analysis was suspected as being two plasmids; this explains the difference in the physical dimensions of the gels in Figs. 4 and 5. Gels were stained in ethidium bromide solution and examined by standard procedures. The molecular sizes of the resolved plasmid DNA were measured with an Alpha
Innotec Gel Documentation System (Flowgen). Plasmid standards were derived from Escherichia coli strain 39R861 (which contains plasmids of 98.0, 42.0, 23.9 and 4.6 MDa) [50, 51]. Standards comprised covalently closed circular plasmid DNA.

\section{Results}

The bulk of the new experimental data is concerned with analyses of plasmid and LPS profiles that are correlated with pre-existing invasion data (Table 1).

\section{LPS profiles of Enteritidis strains $P T 4$ and $P T 7$ and Typhimurium strains TML, WAKE, W118, SL1027, Thax-1, M206 and LT7}

The LPS profiles are shown in Fig. 1. Enteritidis PT 4 expressed a long-chain LPS profile (high mol. wt ladder, lane 1) and PT 7 a 'rough' LPS profile (complete absence of high mol. wt ladder, lane 2); these served as controls for SDS-PAGE and silver staining. Strains TML, WAKE, W118, SL1027, Thax1, M206 and LT7 all expressed long-chain LPS, as evidenced by the high mol. wt ladder region seen in lanes 3-9 respectively. The lack of resolution in the lower part of the gel in lanes 7 and 8 is a technical artefact which does not affect the interpretation of the LPS status of Thax-1 and M206 as smooth, as both lanes show typical high mol. wt ladders indicative of long-chain LPS. A slight difference in the banding

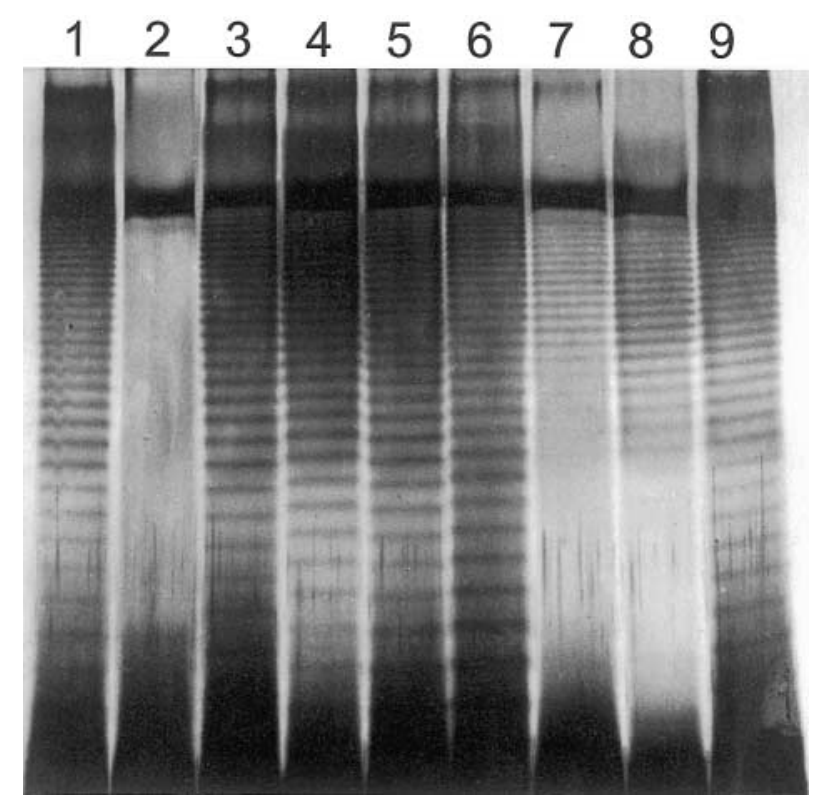

Fig. 1. LPS profiles of Typhimurium strains TML, WAKE, W118, SL1027, Thax-1, M206 and LT7, and Enteritidis strains PT 4 and PT 7. Lane 1, PT 4; 2, PT 7; 3, TML; 4, WAKE; 5, W118; 6, SL1027; 7, Thax-1; 8, M206; 9, LT7. Note that PT 7 shows a classical 'rough' type ladder pattern and TML (lane 3 ), shows a slightly different ladder pattern from the other Typhimurium strains in the lower molecular range. Apart from PT 7, all strains are manifestly smooth. 
pattern of TML was observed in the lower mol. wt range (lane 3 ). See Table 1 for collated summary.

\section{LPS profiles of Typhimurium strains GM1-10}

The profiles are shown in Fig. 2. Strains GM1-10 all expressed long-chain LPS (lanes 1-10 respectively). LPS from Enteritidis PT 4 (lane 11) and Typhimurium LT7 (lane 12) are shown for comparison. Close inspection of lane 9 suggests that the Typhimurium GM9 LPS has a different SDS-PAGE profile from the other Typhimurium strains, but is more like Enteritidis PT 4 (lane 11). See Table 1 for collated summary.

\section{Invasiveness of Enteritidis PT 4 and PT 7}

In previous experiments, it was shown that rough TnphoA mutants of Typhimurium TML were noninvasive [24]. The existence of the Enteritidis PT4 strain and its naturally occurring isogenic PT7 rough derivative provided an opportunity to test the role of LPS free from the kind of criticisms (see Introduction) which can be levelled against the use of rough transposon insertion mutants. Data from three separate experiments show that Enteritidis PT 7 is about half as invasive as Enteritidis PT 4 (Fig. 3); see Table 1 for collated summary.

\section{Plasmid profiles of Typhimurium strains GM1-10}

In a preliminary experiment, Typhimurium GM3, originally thought to be a hypo-invasive strain but now known to be a histotoxic invasive strain [43, 52], was shown not to contain the 60-MDa SSP. This stimulated an examination of the plasmid profiles of

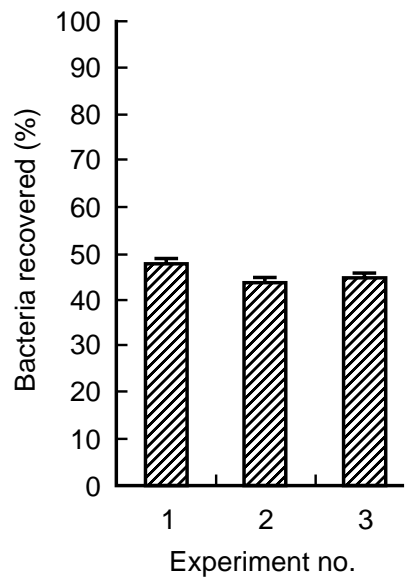

Fig. 3. Invasiveness of Enteritidis PT 4 and PT 7 compared in three experiments. Each column represents one experiment and is the mean $( \pm \mathrm{SD})$ of numbers of tissueprotected bacteria recovered from three chambers for PT 7. The data for PT 7 are normalised to PT 4 (mean of three chambers, $100 \%)$. PT 7 was consistently $\leqslant 50 \%$ as invasive as PT 4.

the GM1-10 series for which quantitative gut invasion data already existed [43]. A variety of plasmid profiles was observed in these strains with no clear correlation between plasmid content or profile and invasiveness (Fig. 4). See Table 1 for collated summary.

\section{Plasmid profiles of Typhimurium strains TML, WAKE, W118, SL1027, Thax-1, M206, LT7 and LT2}

Plasmid profiles of these biologically characterised strains were also determined, as these had not been examined previously and a wealth of gut invasion

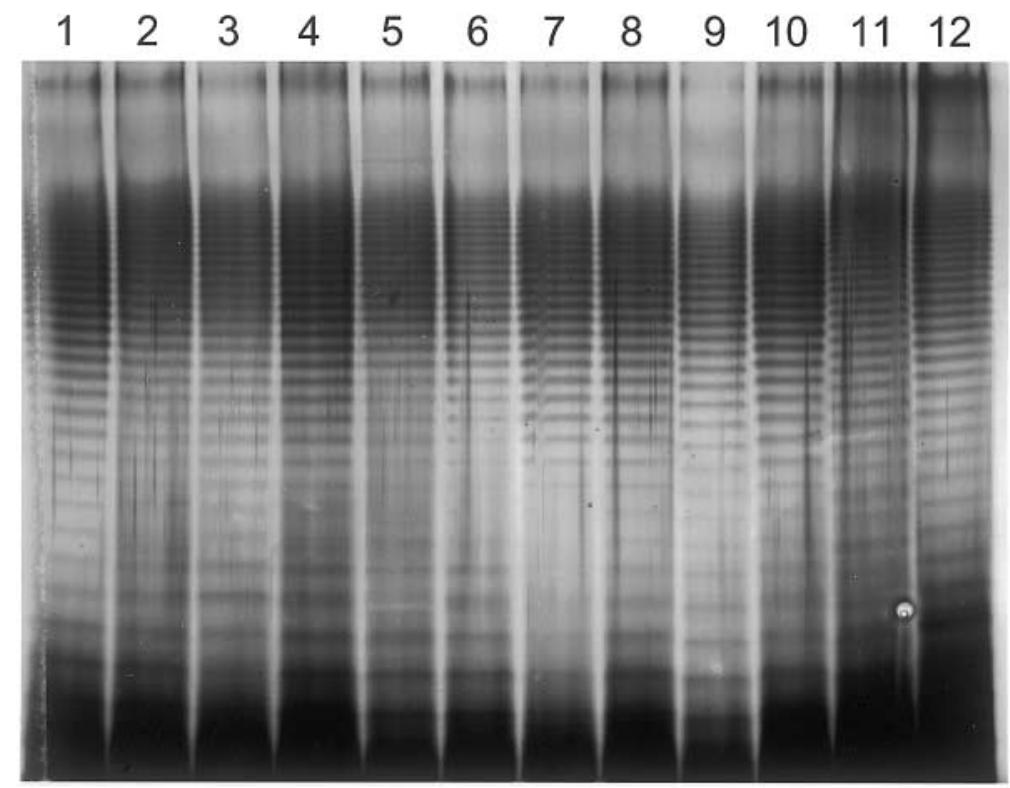

Fig. 2. LPS profiles of Typhimurium strains GM1-10. Lanes 1-10, GM1-GM10 respectively; 11, Enteritidis PT 4; 12, Typhimurium LT7. Note that all strains are smooth and the ladder pattern of GM9 (lane 9) is dissimilar to those of the other GM strains but similar to that of PT 4 (lane 11). 


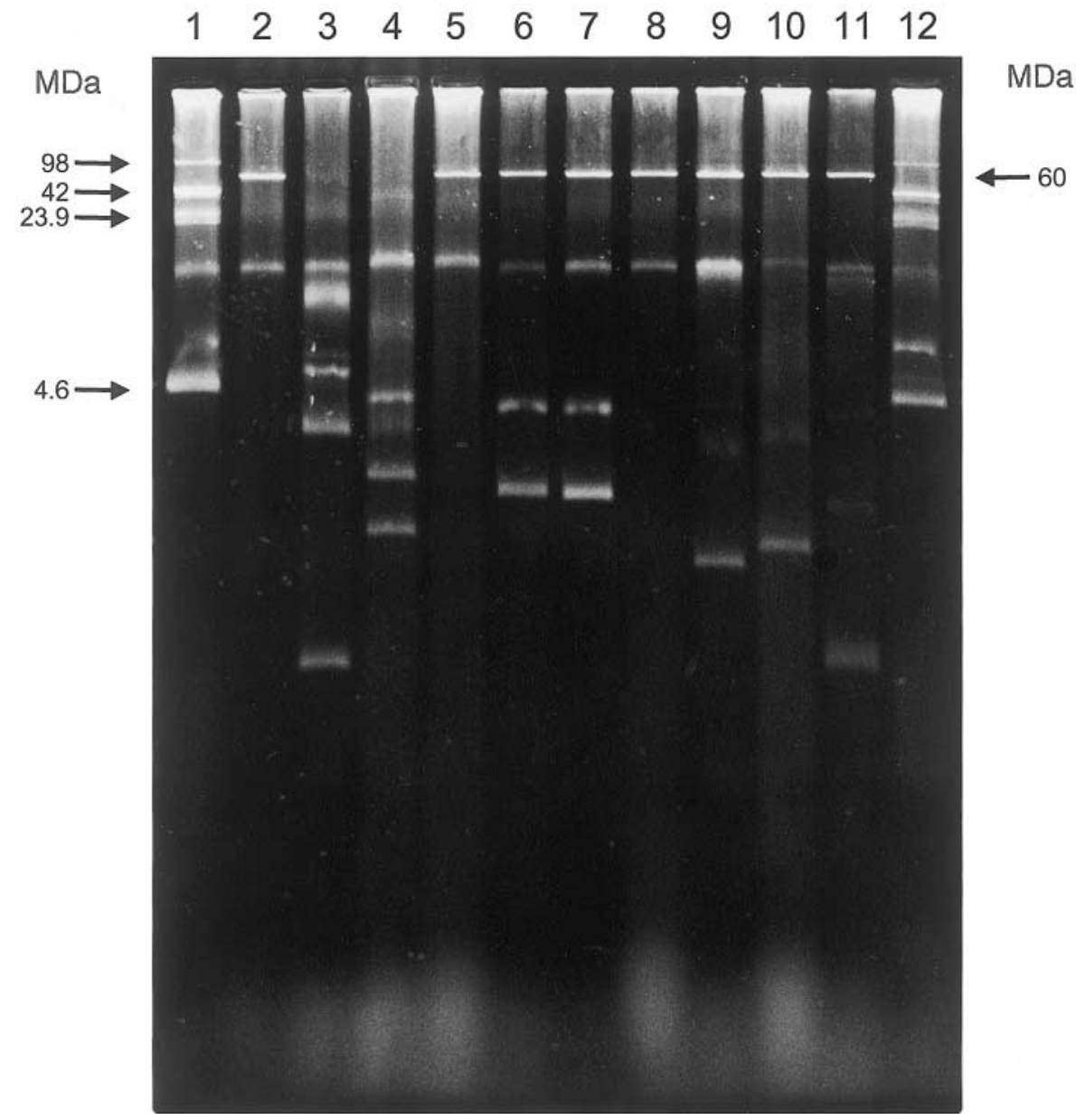

Fig. 4. Plasmid profiles of Typhimurium strains GM1-10. Lanes 1 and 12, standards comprising characterised plasmids from E. coli strain 39R861 [50] of 98.0, 42.0, 23.9 and 4.6 MDa. The band between the 23.9 and 4.6 markers is chromosomal DNA [51]. Lanes 2-11, GM1-10 respectively. The 60-MDa band corresponds to the main SSP of Salmonella serotype Typhimurium; it is absent from GM2 (lane 3) and GM3 (lane 4), although they do contain smaller plasmids.

data existed for these strains (Fig. 5). Virulent invasive strains TML and W118 (each belonging to PT 32, lanes 2 and 4 respectively) had two plasmids of c. $60 \mathrm{MDa}$, whereas the third virulent invasive strain WAKE (PT 49, lane 3) had only one equivalent to the larger plasmid in TML and W118. Of the characterised avirulent hypo-invasive strains, LT7 (lane 8) possessed two large plasmids, SL1027 (lane 5) possessed one large plasmid (equivalent to the larger of the two in lanes 2 and 4). M206 (lane 7) had no detectable plasmids. Thax1 (lane 6) possessed two large plasmids, which produced restriction patterns slightly different from either TML or W118 (not shown). Thus there was no obvious correlation between plasmid profile and virulence in general or invasion in particular. One other strain (LT2, lane 9), was examined in this context as it is widely used in Salmonella genetic analyses and much is known about its plasmid profile [53]; LT2 (lane 9) was similar to SL1027. See Table 1 for collated summary.
Invasiveness of wild-type Enteritidis PT 4 and an isogenic strain of PT 4 lacking the $S$. enteritidis 38-MDa SSP (PT4(-))

In one experiment, the invasiveness of these two strains was similar. The means and SD of recoveries of PT 4 (from four chambers) and PT 4- (from three chambers) were 4.5 (1.5) and 3.5 (1), respectively.

\section{Seasonal variation in invasiveness of Typhimurium for rabbit terminal ileum}

It had been observed over a period of years by several workers in this laboratory that the invasiveness of strains (even hyperinvasive strains) seemed to be less during the high summer period. This was examined in a controlled manner during one period covering January to August with Typhimurium strains TML and LT7 (Fig. 6a, b). In absolute terms, the invasion data showed a degree of variation in these experiments (Fig. 6a) which is beyond the control of the experimenter and presumably reflected the physiologi- 


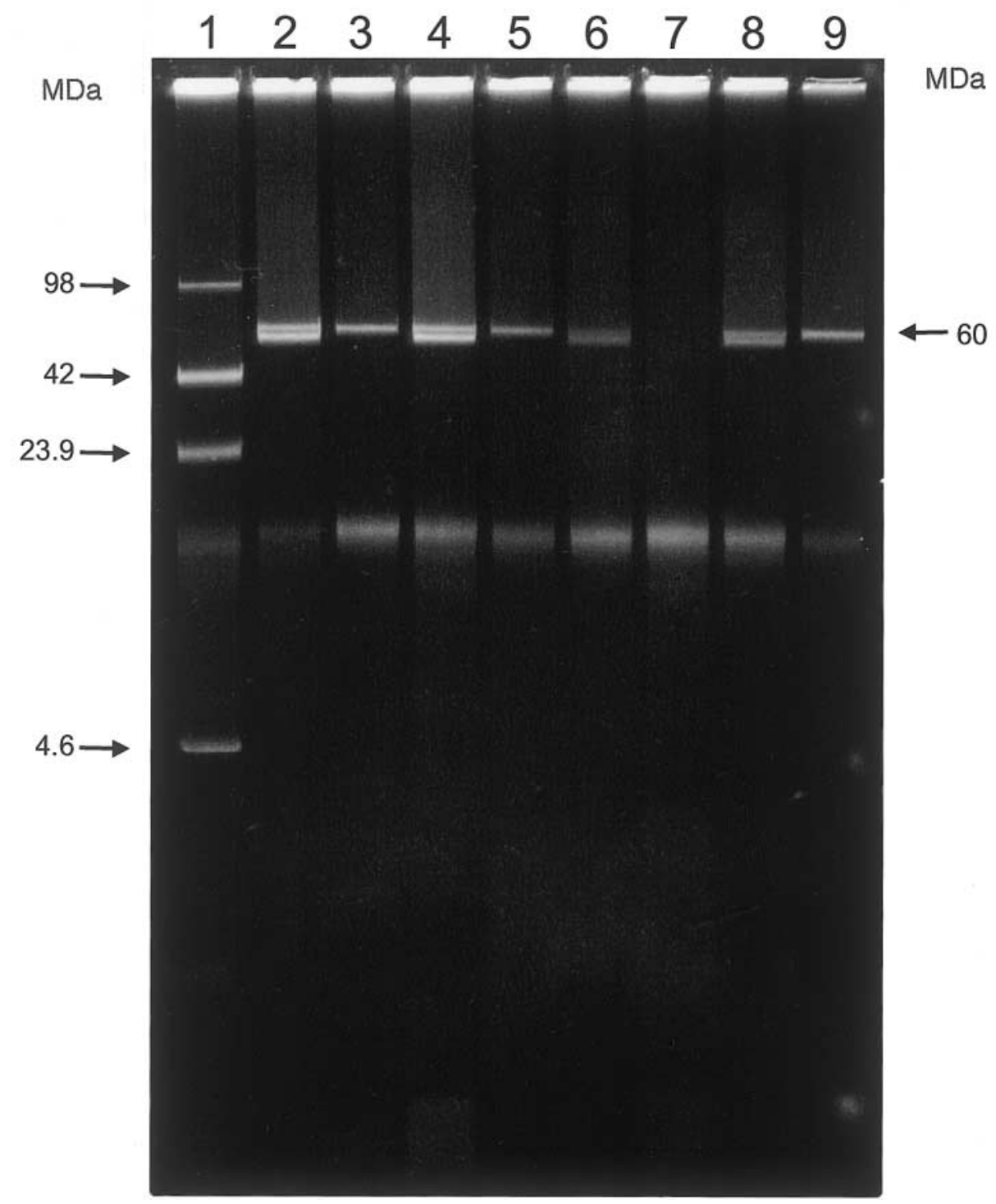

Fig. 5. Plasmid profiles of Typhimurium strains TML, WAKE, W118, SL1027, Thax-1, M206, LT7 and LT2. Lane 1, standards comprising characterised plasmids from E. coli strain 39R861 [50] of 98.0, 42.0, 23.9 and 4.6 MDa. The band between the 23.9 and 4.6 markers is chromosomal DNA [51]. Lane 2, TML; 3, WAKE; 4, W118; 5, SL1027; 6, Thax-1; 7, M206; 8, LT7; 9, LT2.

cal or immunological status of the animals. However, normalising the LT7 data to TML showed that Typhimurium TML can consistently be discriminated from LT7 (Fig. 6b). Previously, the invasiveness of hypo-invasive Typhimurium LT7 had been found to range from 25 - to 100 -fold lower than invasive Typhimurium TML [42]. The 3-40-fold range observed in this work is lower, but of the same order of magnitude. However, the mean value of Typhimurium LT7 normalised to Typhimurium TML was found to be $11 \%$, which is similar to the previously obtained value of $8 \%$ [42]. Possible causes of this phenomenon are discussed below.

\section{Discussion}

Ten recently isolated strains (GM1-10) of Typhimurium were used to examine the role of plasmid carriage in the invasion of rabbit gut epithelia. A variety of plasmid profiles was obtained from which it is deduced that there is no direct correlation between possession of the $60-\mathrm{MDa}$ SSP and the ability to invade rabbit gut epithelia. The main 60-MDa SSP virulence plasmid was absent in Typhimurium strain GM3, the sole member of invasion group 1; it is a histotoxic invasive strain $[43,52]$. SSP was also absent in Typhimurium strain GM2 (invasion group 4), which exhibited 80$100 \%$ of the invasiveness of Typhimurium TML. Not only was there no correlation between invasiveness and possession of the 60-MDa SSP, there was no correlation between overall patterns of plasmid possession and invasiveness. Unlike the situation in Salmonella serotype Enteritidis, in which some 500 strains were examined [54], there were no examples among the Typhimurium strains examined here with virulenceassociated plasmids larger than $60 \mathrm{MDa}$, and none of the strains was plasmid free. 

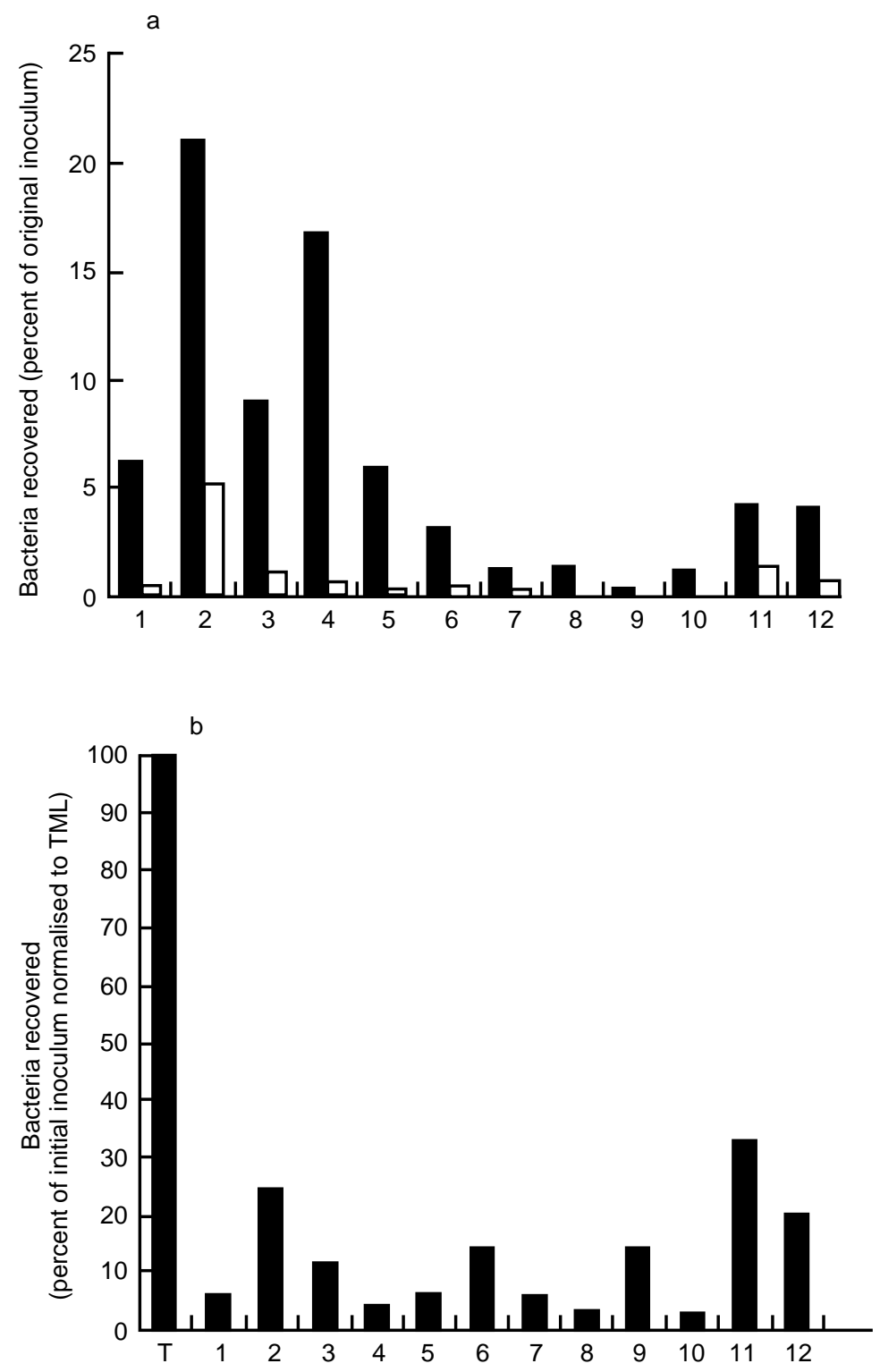

Fig. 6. (a) Seasonal variation in absolute invasiveness of Salmonella serotype Typhimurium for rabbit terminal ileum. Recoveries of Typhimurium strains TML and LT7 from a series of RIIAs conducted over a period from Jan. to Aug. The data are means from a minimum of two (usually three or four) chambers. $\mathbf{0}$, TML; $\square$, LT7. (b) Seasonal consistency in relative invasiveness of Salmonella serotype Typhimurium for rabbit terminal ileum. The same data as in (a), but with LT7 normalised to TML in individual experiments. T, TML set to 100\%. All other columns, LT7 normalised to TML. In both (a) and (b), the numbers correspond to the following dates. 1, Jan; 2, April; 3, 4, May; 58, June; 9,10, July; 11,12, Aug. The data show (i) that absolute values vary (probably reflecting the susceptibility of gut of individual rabbits to invasion), (ii) that there is an apparent seasonality to the variation (tests done during June and July showed rabbit guts to be less susceptible to invasion), but (iii) the pattern of relative invasiveness is reproducible when normalised - even during the summer months.

Examination of the plasmid profiles of the original panel of older, biologically characterised strains (TML, WAKE, W118, SL1027, Thax-1, M206 and LT7) revealed an even more complex pattern of plasmid profile. Two of the virulent invasive strains (TML and W118) and one hypo-invasive strain (LT7) harbour two plasmids of c. $60 \mathrm{MDa}$; coincidentally, TML and W118 are PT 32, whereas LT7 is PT 46. The third virulent strain WAKE, harboured one 60-MDa plasmid, as did the avirulent hypo-invasive strain SL1027; LT2 was similar to SL1027. M206 had no plasmids. Thus, there was no obvious correlation between plasmid profile and gastro-enteritic virulence in general, invasion in particular, or in phage type. However, two additional points should be noted. First, while the collective data presented here constitute persuasive evidence for the non-correlation of plasmid carriage with invasiveness, some caution must still be exercised. For example, the non-invasive avirulent strain Thax-1 possessed two large plasmids of $c$. $60 \mathrm{MDa}$, but these produced 
restriction patterns slightly different from either TML or W118 (data not shown). Clearly it would require plasmid sequence analyses to make definitive statements. The one experiment with Enteritidis PT 4 and plasmid-free PT4(-) strains also points to the noninvolvement of plasmids in invasiveness of Enteritidis PT 4; unfortunately, for logistical reasons, these experiments were not repeated - hence they lack the weight of statistical significance. The second point relates to the plasmid profiles of strains TML, W118 and LT7, each of which has two plasmids of $c$. $60 \mathrm{MDa}$. Strain TML was previously shown to have both a 60-MDa plasmid (designated 'cryptic' plasmid or pSLT) and a colicin plasmid of similar size [55]; the agarose gel profiles are remarkably similar to those reported here. TML derivatives that no longer harboured the autonomous 60-MDa plasmid were significantly less adhesive and invasive for HeLa cells. This result is in disagreement with the synthesis given above for differentiated gut. Later, both TML and W118 were reported [56] to possess a colicin plasmid in addition to a $90-\mathrm{kb}$ plasmid (presumed equivalent of the 60-MDa SSPs). No size was ascribed to the colicin plasmid [56] and as col plasmids are known to vary in size it is probable that the second band in the gel profiles presented here could be the colicin plasmid of that report [56], as no other plasmids were detected. Similarly, strain LT7 is known to harbour a colicin, which was the basis of its rejection for early systematic studies on Salmonella genetics [53].

The situation regarding plasmids and invasion of gut by Salmonella is quite different from that in Shigella flexneri [57] in which plasmid-borne genes play crucial roles in colonic epithelial invasion.

As regards the role of long-chain LPS, it has been shown here that hypo-invasive Typhimurium strains (LT7, SL1027, Thax-1 and M206) expressed long-chain LPS which cannot therefore be a primary determinant of invasiveness for rabbit gut. However, the data from the Enteritidis experiments provide persuasive evidence that LPS does contribute to invasiveness. Enteritidis PT 7 is a spontaneously arising mutant from PT 4 without laboratory manipulation, which makes these strains ideal for comparative analysis. However, in view of the data from the Typhimurium strains examined, it is unlikely that LPS can be the primary component that mediates invasion; the normal gut is full of organisms expressing LPS. It is much more likely that, as highlighted in the Introduction, LPS exerts a secondary role which could be determined by the length of the side-chain, the detailed chemical structure of the repeat units, steric effects exerted on the orientation of some crucial surface protein or in the secretion of the actual invasins. These kinds of effects would reflect in reduced invasiveness of otherwise invasive bacteria.

The final comment relates to Figs. $6 a$ and b. Based on the experience of several workers, this pattern of seasonal variability had been suspected for a considerable period of time. There is no doubt that this happens in experiments with Typhimurium strains and rabbit gut explants. Over a period of many years, from the original inception of this programme of research on the pathogenesis of Salmonella-induced diarrhoea with the rabbit as the model for human disease, it has been observed that there are periods during which the inherent susceptibility of the rabbit gut to invasion reflected in fluid secretion in ligated ileal loops or in numbers of tissue-protected organisms in RIIA assays - sometimes varied in a manner that could not readily be predicted, controlled or explained. No satisfactory explanation for this phenomenon has ever been advanced. Present practices at this University prevent the breeding of our own animals and the controlling of environmental and maintenance regimens under which they are kept prior to experiment. All animals are bought in. It is impossible to obtain verifiable statements about the health of animals from commercial breeders: they are always healthy! One possible scenario is that the animals are 'immune' to Salmonella at certain times of the year because of exposure of the breeding stock to Salmonella or some cross-protecting organism and that such acquired immunity is expressed at the level of primary invasion of the gut and is transient. If this were to be proved it could be a highly significant finding. Such observations serve as a reminder that the physiological status of potentially susceptible hosts is very important when attempting to elucidate the basis of host-pathogen interactions.

From the results presented here it is concluded that (i) there is no evidence to suggest that plasmids play a major role in the primary invasiveness of Typhimurium and Enteritidis for rabbit gut epithelia, (ii) long-chain LPS plays a secondary role in invasiveness of Enteritidis for rabbit gut epithelia and (iii) other as yet unidentified host factors significantly affect the susceptibility of rabbit gut epithelia to invasiveness of Typhimurium.

We thank The Wellcome Trust for grant support to J.M.L., N.L.B. and J.S., the BBSRC for studentship to G.D.M. and the MRC for studentship to E.M.

\section{References}

1. Levin J, Alving CR, Munford RS, Stotz PL (eds). Bacterial endotoxin: recognition and effector mechanisms, vol 2 . Endotoxin Research Series. Elsevier Science Publishers BV. 1993.

2. Levin J, van Deventer SJH, van der Poll T, Sturk A (eds). Bacterial endotoxins. Basic science to anti-sepsis strategies. Progress in clinical and biological research, vol 388. New York, John Wiley \& Sons Inc. 1994.

3. Levin J, Alving CR, Munford RS, Redl H (eds). Bacterial endotoxins. Lipopolysaccharides from genes to therapy. Progress in clinical and biological research, vol 392. New York, John Wiley \& Sons Inc. 1995.

4. Whitfield C. Biosynthesis of lipopolysaccharide O -antigens. Trends Microbiol 1995; 3: 178-185.

5. Maskell D, Allen A. Molecular biology of lipopolysaccharide 
biosynthesis in Salmonella and Bordetella. Biochem Soc Trans 1997; 25: 850-856.

6. Khan SA, Everest P, Servos S et al. A lethal role for lipid A in Salmonella infections. Mol Microbiol 1998; 29: 571-579.

7. Roantree RJ. Salmonella O -antigens and virulence. Annu Rev Microbiol 1967; 21: 443-466.

8. Nakano M, Saito K. Chemical components in the cell wall of Salmonella typhimurium affecting its virulence and immunogenicity in mice. Nature 1969; 222: 1085-1086.

9. Germanier R. Immunity in experimental salmonellosis. I. Protection induced by rough mutants of Salmonella typhimurium. Infect Immun 1970; 2: 309-315.

10. Valtonen VV. Mouse virulence of Salmonella strains: the effect of different smooth-type O-side chains. J Gen Microbiol 1970; 64: $255-268$.

11. Mäkelä PH, Valtonen VV, Valtonen MV. Role of O-antigen (lipopolysaccharide) factors in the virulence of Salmonella. $J$ Infect Dis 1973; 128: S81-S85.

12. Valtonen MV. Role of phagocytosis in mouse virulence of Salmonella typhimurium recombinants with $\mathrm{O}$-antigen 6,7 or 4,12. Infect Immun 1977; 18: 574-582.

13. Liang-Takasaki C-J, Mäkelä PH, Leive L. Phagocytosis of bacteria by macrophages: changing the carbohydrate of lipopolysaccharide alters interaction with complement and macrophages. J Immunol 1982; 128: 1229-1235.

14. Liang-Takasaki C-J, Grossman N, Leive L. Salmonellae activate complement differentially via the alternative pathway depending on the structure of their lipopolysaccharide O-antigen. J Immunol 1983; 130: 1867-1870.

15. Grossman N, Leive L. Complement activation via the alternative pathway by purified Salmonella lipopolysaccharide is affected by its structure but not its O-antigen length. J Immunol 1984; 132: 376-385.

16. Saxen H, Hovi M, Makela PH. Lipopolysaccharide and mouse virulence of Salmonella: O-antigen is important after intraperitoneal but not intravenous challenge. FEMS Microbiol Lett 1984; 24: 63-66.

17. Saxén H, Reima I, Mäkelä PH. Alternative complement pathway activation by Salmonella O-polysaccharide as a virulence determinant in the mouse. Microb Pathog 1987; 2: 15-28.

18. Tannock GW, Blumershine RVH, Savage DC. Association of Salmonella typhimurium, with, and its invasion of, the ileal mucosa in mice. Infect Immun 1975; 11: 365-370.

19. Mroczenski-Wildey MJ, Di Fabio JL, Cabello FC. Invasion and lysis of HeLa cell monolayers by Salmonella typhi: the role of lipopolysaccharide. Microb Pathog 1989; 6: 143-152.

20. Mintz CS, Deibel RH. Effect of Lipopolysaccharide mutations on the pathogenesis of experimental Salmonella gastroenteritis. Infect Immun 1983; 40: 236-244.

21. Finlay BB, Gumbiner B, Falkow S. Penetration of Salmonella through a polarized Madin-Darby Canine Kidney epithelial cell monolayer. J Cell Biol 1988; 107: 221-230.

22. Kihlström E. The effects of lipopolysaccharides on the association of Salmonella typhimurium with HeLa cells. Scand $J$ Infect Dis 1980; 24: S141-S143.

23. Gahring LC, Heffron F, Finlay BB, Falkow S. Invasion and replication of Salmonella typhimurium in animal cells. Infect Immun 1990; 58: 443-448.

24. Lodge J, Douce GR, Amin II et al. Biological and genetic characterization of $\operatorname{Tn} p h o A$ mutants of Salmonella typhimurium TML in the context of gastroenteritis. Infect Immun 1995; 63: $762-769$

25. Blackwell JM. Bacterial infections. In: Wakelin D, Blackwell JM (eds) Genetics of resistance to bacterial and parasitic infection. London, Taylor \& Francis. 1988: 63-101.

26. Chart H, Rowe B. Antibodies to lipopolysaccharide and outer membrane proteins of Salmonella enteritidis PT4 are not involved in protection from experimental infection. FEMS Microbiol Lett 1991; 84: 345-350.

27. Hormaeche CE, Villarreal B, Mastroeni P, Dougan G, Chatfield $\mathrm{SN}$. Immunity mechanisms in experimental salmonellosis. In: Cabello F, Hormaeche C, Mastroeni P, Bonina L (eds) Biology of Salmonella (NATO ASI Series A245). New York, Plenum Press. 1993: 223-235.

28. Ernst RK, Guina T, Miller SI. How intracellular bacteria survive: surface modifications that promote resistance to host innate immune responses. J Infect Dis 1999; 179 Suppl 2: S326-S330.
29. Gunn JS, Lim KB, Krueger J et al. PmrA-PmrB-regulated genes necessary for 4-aminoarabinose lipid A modification and polymyxin resistance. Mol Microbiol 1998; 27: 1171-1182.

30. Stone BJ, Miller VL. Salmonella enteritidis has a homologue of tolC that is required for virulence in BALB/c mice. Mol Microbiol 1995; 17: 701-712.

31. Guard-Petter J, Keller LH, Rahman MM, Carlson RW, Silvers $\mathrm{S}$. A novel relationship between $\mathrm{O}$-antigen variation, matrix formation, and invasiveness of Salmonella enteritidis. Epidemiol Infect 1996; 117: 219-231.

32. Darwin KH, Miller VL. Molecular basis of the interaction of Salmonella with the intestinal mucosa. Clin Microbiol Rev 1999; 12: 405-428.

33. Groisman EA, Blanc-Potard A-B, Uchiya K. Pathogenicity islands and the evolution of Salmonella virulence. In: Kaper JB, Hacker J (eds) Pathogenicity islands and other mobile virulence elements. Washington, DC, ASM Press. 1999: $127-150$.

34. Barrow PA, Simpson JM, Lovell MA, Binns MM. Contribution of Salmonella gallinarum large plasmid toward virulence in fowl typhoid. Infect Immun 1987; 55: 388-392.

35. Woodward MJ, McLaren I, Wray C. Distribution of virulence plasmids within Salmonellae. J Gen Microbiol 1989; 135: 503-511.

36. Lax AJ, Barrow PA, Jones PW, Wallis TS. Current perspectives in salmonellosis. $B r$ Vet $J$ 1995; 151: 351-377.

37. Wallis TS, Paulin SM, Plested JS, Watson PR, Jones PW. The Salmonella dublin virulence plasmid mediates systemic but not enteric phases of salmonellosis in cattle. Infect Immun 1995; 63: $2755-2761$.

38. Finch MJ, Franco A, Gotuzzo E et al. Plasmids in Salmonella typhi in Lima, Peru, 1987-1988: epidemiology and lack of association with severity of illness or clinical complications. Am J Trop Med Hyg 1992; 47: 390-396.

39. Chart H, Threlfall EJ, Powell NG, Rowe B. Serum survival and plasmid possession by strains of Salmonella enteritidis, Salm. typhimurium and Salm. virchow. J Appl Bacteriol 1996; 80: $31-36$.

40. Manning EJ, Baird GD, Jones PW. The role of plasmid genes in the pathogenicity of Salmonella dublin. J Med Microbiol 1986; 21: 239-243.

41. Pardon P, Popoff MY, Coynault C, Marly J, Miras I. Virulenceassociated plasmids of Salmonella serotype Typhimurium in experimental murine infection. Ann Inst Pasteur Microbiol 1986; 137B: 47-60.

42. Amin II, Douce GR, Osborne MP, Stephen J. Quantitative studies of invasion of rabbit ileal mucosa by Salmonella typhimurium strains which differ in virulence in a model of gastroenteritis. Infect Immun 1994; 62: 569-578.

43. Bolton AJ, Martin GD, Osborne MP, Wallis TS, Stephen J. Invasiveness of Salmonella serotypes Typhimurium, Choleraesuis and Dublin for rabbit terminal ileum in vitro. J Med Microbiol 1999; 48: 800-810.

44. Wallis TS, Starkey WG, Stephen J, Haddon SJ, Osborne MP, Candy DCA. Enterotoxin production by Salmonella typhimurium strains of different virulence. J Med Microbiol 1986; 21: 19-23.

45. Wallis TS, Starkey WG, Stephen J, Haddon SJ, Osborne MP, Candy DCA. The nature and role of mucosal damage in relation to Salmonella typhimurium-induced fluid secretion in the rabbit ileum. $J$ Med Microbiol 1986; 22: 39-49.

46. Wallis TS, Hawker RJH, Candy DCA et al. Quantification of the leucocyte influx into rabbit ileal loops induced by strains of Salmonella typhimurium of different virulence. $J$ Med Microbiol 1989; 30: 149-156.

47. Chart H, Rowe B, Threlfall EJ, Ward LR. Conversion of Salmonella enteritidis phage type 4 to phage type -7 involves loss of lipopolysaccharide with concomitant loss of virulence. FEMS Microbiol Lett 1989; 60: 37-40.

48. Tsai C-M, Frasch CE. A sensitive silver stain for detecting lipopolysaccharides in polyacrylamide gels. Anal Biochem 1982; 119: 115-119.

49. Kado CI, Liu S-T. Rapid procedure for detection and isolation of large and small plasmids. $J$ Bacteriol 1981; 145: $1365-1373$.

50. Threlfall EJ, Rowe B, Ferguson JL, Ward LR. Characterization of plasmids conferring resistance to gentamicin and apramycin in strains of Salmonella typhimurium phage type 204c isolated 
in Britain. $J$ Hyg 1986; 97: 419-426.

51. Woodford N, Johnson AP, Threlfall EJ. Extraction and fingerprinting of bacterial plasmids. In: Chart $\mathrm{H}$ (ed) Methods in practical laboratory bacteriology. Boca Raton FL, CRC Press. 1994: 93-105.

52. Lodge JM, Bolton AJ, Martin GD, Osborne MP, Ketley JM, Stephen J. A histotoxin produced by Salmonella. J Med Microbiol 1999; 48: 811-818.

53. Sanderson KE, Hessel A, Stocker BAD. Strains of Salmonella typhimurium and other Salmonella species used in genetic analysis. In: Neidhart FC, Curtiss R, Ingrahan JL (eds) Escherichia coli and Salmonella: cellular and molecular biology, 2nd edn, vol 2. Washington, DC, ASM Press. 1996: 2496-2503.

54 Threlfall EJ, Hampton MD, Chart H, Rowe B. Use of plasmid profile typing for surveillance of Salmonella enteritidis phage type 4 from humans, poultry and eggs. Epidemiol Infect 1994; 112: $25-31$.

55. Jones GW, Rabert DK, Svinarich DM, Whitfield HJ. Association of adhesive, invasive, and virulent phenotypes of Salmonella typhimurium with autonomous 60-megadalton plasmids. Infect Immun 1982; 38: 476-486.

56. Ou JT, Baron LS. Strain differences in expression of virulence by the 90 kilobase pair virulence plasmid of Salmonella serovar Typhimurium. Microb Pathog 1991; 10: 247-251.

57. Sansonetti PJ, Kopecko DJ, Formal SB. Involvement of a plasmid in the invasive ability of Shigella flexneri. Infect Immun 1982; 35: 852-860. 